\title{
Analysis of Education Wage Premium in Several Provinces of China
}

\author{
Xinyang Chang \\ Business School, Beijing Normal University, Beijing, China \\ Email: cxybnu@126.com
}

Received 14 July 2015; accepted 2 August 2015; published 5 August 2015

Copyright (C 2015 by author and Scientific Research Publishing Inc.

This work is licensed under the Creative Commons Attribution International License (CC BY). http://creativecommons.org/licenses/by/4.0/

\section{(c) (i) Open Access}

\begin{abstract}
By using the CHIP-2007 data, this paper builds a model based on the Mincer wage equation model, and analyses the education wage premium of three levels of education-"junior middle school and the following", "high school or technical secondary school", and "junior college or above" in several provinces of China by the OLS estimation method. The analysis results show that the wage income of workers in China increases with the improvement of education level. There does exist the education wage premium. There isn't the phenomenon that the intellectual workers get less wage income than manual workers. Education wage premium of the population of tertiary and higher education level is much higher than that of the population of high school or secondary school education level.
\end{abstract}

\section{Keywords}

Education Wage Premium, the Mincer Wage Equation Model, Education Level

\section{Introduction}

Wage premium is affected by many factors, which includes education wage premium, industry wage premium, and regional wage premium and so on. Education wage premium capital refers to the relative wages of education capital, such as human resource investment, labor union intervention, economic development level, industry, region, legal system and social insurance. Education capital can be classified into two categories: high and low educational capital. Education wage premium is defined as the ratio of high educational capital wage to low educational capital wage, which is represented as the college wage premium (the ratio of wage of college graduates to wage of high school graduates). The impact of education on earnings, income inequality and educational capital wage premium has been widely discussed both in abroad and China. The research of wage premium for education capital starts in western countries. Since 1960s, proportion of labor force with high education capital has been increasing, while education wage premium keeps rising. According to the study of Acemoglu, the propor- 
tion of American college graduates among the whole population has been increasing. At the same time, from 1979 to 1995, American education wage premium returns on capital increased by about 25\%. Since the 1960s, various theories on education wage premium have occurred. Becker (1964) explained education wage premium in the perspective of human capital investment capital. After years of study, Mincer (1974) concluded that education level and work experience could explain 33\% of income inequality of American in 1959. He proposed a method to estimate individual returns to education-“Mincer wage equation”. Due to ease of operation, Mincer wage equation has become a common analysis method on educational investment cost-benefit since the 1980s. Psacharopoulos (1985) concluded that the return to the lower level of education in developing countries was about 15\%, much higher than the yield of material capital investments by estimating the returns to education in more than 60 countries. Yankow (2006) found that the wage premium in US cities was 19\%, which would decrease to one third by controlling the difference of labor itself through fixed effects. In other word, unobservable labor quality could explain quite a part of US cities wage premium (Glaeser, Mare, 2001; Wheeler, 2001). Fang (2006) thought that college education could improve productivity by $40 \%$, which can explain two thirds of the wage gap between college graduates and those who never attended college.

There are mainly two theories on education wage premium. Schultz (1961) put forward a human capital theory, which was improved by Becker (1964) and Mincer (1974) and the theory of signal detection. Human capital theory thought that workers with high level of education could get high wage because of their high productivity. Spencer came up with the theory of signal detection, considering that well-educated workers could get high wage because high level of education was the signal of innate ability. In addition, according to other theories, some researchers believe that the supply and demand of high level education labor decide the level of education wage premium. Richard B. Freeman (1975) examined the relationship between the quick increase of college enrollment rates in the 1960s and the sharp decrease of college wage premium, and found that the result of relative excess college graduates labor. Katz and Murphy (1992) and Taber (2001) proposed two important theories on the impact of the supply of college graduates on the college wage premium. One took tendency of college wage premium into consideration and concluded that the change of the premium was caused by the change of the supply of college graduates. The other tended to explain the phenomenon with the increasing demand of unviable labor quality rather than the increasing demand of skills learnt in college.

Focus on domestic research about the impact of education on wage, the college wage premium was quite low in China at the beginning of the reform and opening up. Even intellectual workers earned less than manual workers generally in 1980s. With the rapid development of China's economy and the deepening of reform and education improvement, the influences of market mechanism in China have been increasing. The proportion of college graduates in the working population is increasing. The impact of education on income distribution has become increasingly prominent. Rate of return to education has been constantly increasing. By summarizing previous studies, Sun Zhijun (2004) found that Chinese urban residents' rate of returns to education were on the rise: in the 1980s it was around 3\%, which rose to 5\% in the mid-1990s. Li Shi and Ding Sai (2003) carried out the research on the long-term trend of Chinese urban residents' rate of returns to education, concluding that the return to education had been increasing in the 1990s. Lai Desheng estimated the rate of return to education in China with the 1995 National income distribution survey data, proving the phenomenon of which the intellectual workers get less wage income than manual workers didn't exist in China. Huang Feng, Wu Chunjie (2008) studied Chinese capital city wage premium with quantile regression method. Bai Xuemei and Li Ying carried on a research about influence of education on income of Chinese citizen with quantile regression method. Zuo Wenting discussed how the education return changes in long trend with CGSS2008 data. Xing Chunbing, Jia Shuyan and Li Shi compared education return in different provinces in China [1]-[13].

Phenomenon of uneven distribution of income is relatively serious currently in China, with the income gap expanding. Education is one of the important factors of income inequality. It's of great importance to study about education capital wage premium to advance understanding income gap of Chinese residents and to make better policies. Nowadays most current studies on educational wage premium take the college wage premium as research objects, lack of micro-data analysis, especially latest data analysis. This paper takes both urban residents and rural labor force as research objects to analyses the education wage premium of 16 - 60 year-old labor force in some Chinese provinces, modeling with Chinese Household Income Project Survey data in 2007. The rest of the paper is organized as follows: the second section describes the model and estimation methods; and the third part is the data and variable description; the fourth part reports estimation and analyses results of interpretation; the fifth part discusses the main findings and policy implications. 


\section{The Model and the Estimation Method}

Mincer wage equation is the common method to estimate college wage premium. This paper adopts the Mincer wage equation to estimate wage premium, based on the characteristics of the study and the data. It is necessary to extend the equation, since the current study adds junior middle school and the following, high school or technical secondary school, college degree and above the three levels of education. Build a new model based on Mincer wage equation. The standard form of Mincer wage equation:

$$
\ln Y=\alpha+\beta_{1} E d u+\beta_{2} \operatorname{Exp}+\beta_{3} \operatorname{Exp}^{2}+\varepsilon
$$

In the equation, $\ln Y$ represents for logarithmic form of wage, Edu for years of education, Exp for years of working, $\operatorname{Exp}^{2}$ for the square of working years to reflect the nonlinear relationship between work experience and income. $\alpha$ is intercept term. $\varepsilon$ is the random error term, and $\beta_{1}, \beta_{2}, \beta_{3}$ are the corresponding variable regression coefficient. $\beta_{1}$ represents the ratio of personal income increased when a worker gets one more year of education. The current study conduct the research on education wage premium, which refers to the ratio of high education capital labor wages to low education capital labor wage. Thus, the researcher uses three adjacent levels of education, junior middle school and the following, high school or technical secondary school, college and above education wage premium for research purpose. This paper gets the results that reflect the overall characteristics of the education returns by estimating with Equation (2.1). Because the key variable"years of education" essentially contains many different levels of education. The more years of education, the more education level workers get through. In this way, it is highly possible that return to education could have different characters. To extend the model further, it is necessary and reasonable to replace the years of education into three adjacent education levels. Considering the definition of education wage premium, premium mainly compares two adjacent education level of the income difference of laborer. This paper chooses the middle level education of high school or technical secondary school education degree as the control group, the junior middle school and the following, junior college or above education degree as the experimental group to analysis. Thus, this study preliminary extended wage equation is:

$$
\ln Y=\alpha+\gamma_{1} E d u_{1}+\gamma_{3} E d u_{3}+\beta_{2} \operatorname{Exp}+\beta_{3} \operatorname{Exp}^{2}+\varepsilon
$$

$E d u_{1}, E d u_{3}$ represent the junior middle school and the following levels of education and college and above education level. $\gamma_{1}, \gamma_{3}$ are regression coefficients of dummy variable for two level of education.

Mincer wage equation only considers the effects of the two forms of impact of human capital to wages: knowledge acquired from school education, and skills accumulated from work practice. However, factors that affect education wage premium also include gender, urban and rural, regional, industry and so on. It is necessary to eliminate other factors that influence education wage premium as much as possible to see how much education capital variables directly impact on the wage premium. Obviously existing variables are not enough; therefore it is of necessity to expand the model further. Gender, urban or rural areas, province three dummy variables are added as control variables to eliminate other influence.

Therefore, this study further expansion of wage equation forms as follows:

$$
\ln Y=\alpha+\gamma_{1} E d u_{1}+\gamma_{3} E d u_{3}+\beta_{2} E x p+\beta_{3} \operatorname{Exp}^{2}+\beta_{4 G} \text { Gender }+\beta_{5} \text { Location }+\beta_{6} \text { Prov }+\varepsilon
$$

Gender, Location, Prov respectively correspond to three dummy variables, Gender, urban or rural areas, the province. $\beta_{4}, \beta_{5}, \beta_{6}$ are regression coefficients for the three dummy variables. Prov contains dummy variable on behalf of eight provinces and cities. As these variables are class variables, the researcher chooses one as the control group. This paper selects Henan province as the control group. So that the current study can not only eliminate the influence of gender, urban and rural, province regional on education wage premium, but also observe and analyze various structural characteristics of education wage premium, so as to conduct more accurate and meticulous research on the education wage premium.

\section{Data and Variable Description}

This study itself bases on Chinese Household Income Project Survey conducted by Institute of Economics Chinese Academy of Social Sciences Income Distribution Group together with National Bureau of Statistics of China in 2007. The data is quite authoritative especially in income research. Therefore we choose it, though the 
data is 8 years ago, it is the latest edition that is available. Mover, wage structure in China does not change a lot, the old data will not influence the accuracy of the research. Sample of the urban household survey in 2007 covers Beijing, Shanxi, Liaoning, Shanghai, Jiangsu, Zhejiang, Anhui, Fujian, Henan, Hubei, Hunan, Guangdong, Chongqing, Sichuan, Yunnan, Gansu 16 provinces and cities. Rural samples include Beijing, Hebei, Shanxi, Liaoning, Jiangsu, Zhejiang, Anhui, Fujian, Henan, Hubei, Hunan, Guangdong, Chongqing, Sichuan, Yunnan, Gansu 16 provinces and cities. Because the provinces of rural samples and urban samples do not match perfectly, this paper eliminates some samples that are not match or not complete. At the end, the researcher chooses Jiangsu, Zhejiang, Anhui, Henan, Hubei, Guangdong, Chongqing, Sichuan eight provinces and cities as sample data. To make it easy to compare, the current research divides the provinces into 3 categories, Jiangsu, Zhejiang, Guangdong as the representatives of the eastern region, Anhui, Henan, Hubei, as representatives of central region, Sichuan and Chongqing to represent the western region. In addition, this paper only considers employed samples, only the employed labors between 16 years old to 60 years old are included, with neither self-employed nor the unemployed without income that very year. The final data includes 8837 samples of the "junior middle school and the following", 3536 samples of the "high school or technical secondary school", 2177 samples of the "junior college or above", 14726 in total.

As this research object is the education wage premium, focus on mainly about the wage difference between workers of two adjacent level of education, mainly considering education degree (or years of education), work experience, gender, urban and rural differences, regional differences and other factors. Lacking of rural high level education samples in CHIP—2007 data , this paper adjust the education level of rural samples into "junior middle school and the following", "high school or college", "college degree and above". This paper uses the equation "years of working $=$ [age $-($ years of education +7$)]$ " to figure work experience. This research sets up a series of dummy variables to respectively control gender differences, urban and rural differences and regional differences. As to wage samples, the paper adopts the annual wage income, excluding non-wage income. From the distribution of the sample variables at different education levels, logarithmic form of the annual wage income of college and above education level is 9.89, high school or technical secondary school education degree is 9.52, the junior middle school and the education degree is 9.47. It shows that samples of junior college or above education degree crowd has the highest average wages, high school or technical secondary school education are in the middle and junior high school and the following level are the lowest. Though male samples are slightly more than female samples, but similar, which accords with the demographic characters. The average working years is 18.89 years. Samples of junior college or above generally get more work experience than the other two groups of education level. The statistical results of other variables in the sample are shown in Table 1.

\section{Estimation Results and Analysis}

To analyze the generality of education wage premium features and the overall impact of work experience to personal wage premium, this paper estimates based on (2.2) in OLS method. The results are shown in Table 2. Except for edu1 (the dummy variable junior middle school and the following), other variables are statistically significant.

The regression coefficient of the variable edu3 (junior college or above) was 0.3471 , it implies that after work experience factor controlled, wage of those who get junior college or above degree is $34.71 \%$ higher than others. In other word, the education wage premium of junior college or above level is $34.71 \%$. The regression result of edu1 (junior middle school and the following) is not statistically significant, which means that in the control of the work experience, there is no significant difference in wage between the junior middle school and the following education degree group and high school or technical secondary school group. The education wage premium of high school or technical secondary school education stage is roughly zero. This may be caused by a lack of variables. Other variables interferes the result. To a certain extent, it reflects the phenomenon that income difference among low education level is not big, whose wage is generally low. The phenomenon that the intellectual workers get less wage income than manual workers doesn't exist in China. Though it has been reported that migrant workers even earns more than college graduates in some industry. It does exist in some special industry, but the fact cannot reflect the average income distribution, and with the increase of work experience, the phenomenon decreases. Some articles on education return in China also have got the same conclusion as this paper.

The regression coefficient of exp (years of working) is 0.0228 . It means that after controlling factors education factors, workers' wages increases by $2.28 \%$, with each additional year of work experience. While coeffi- 


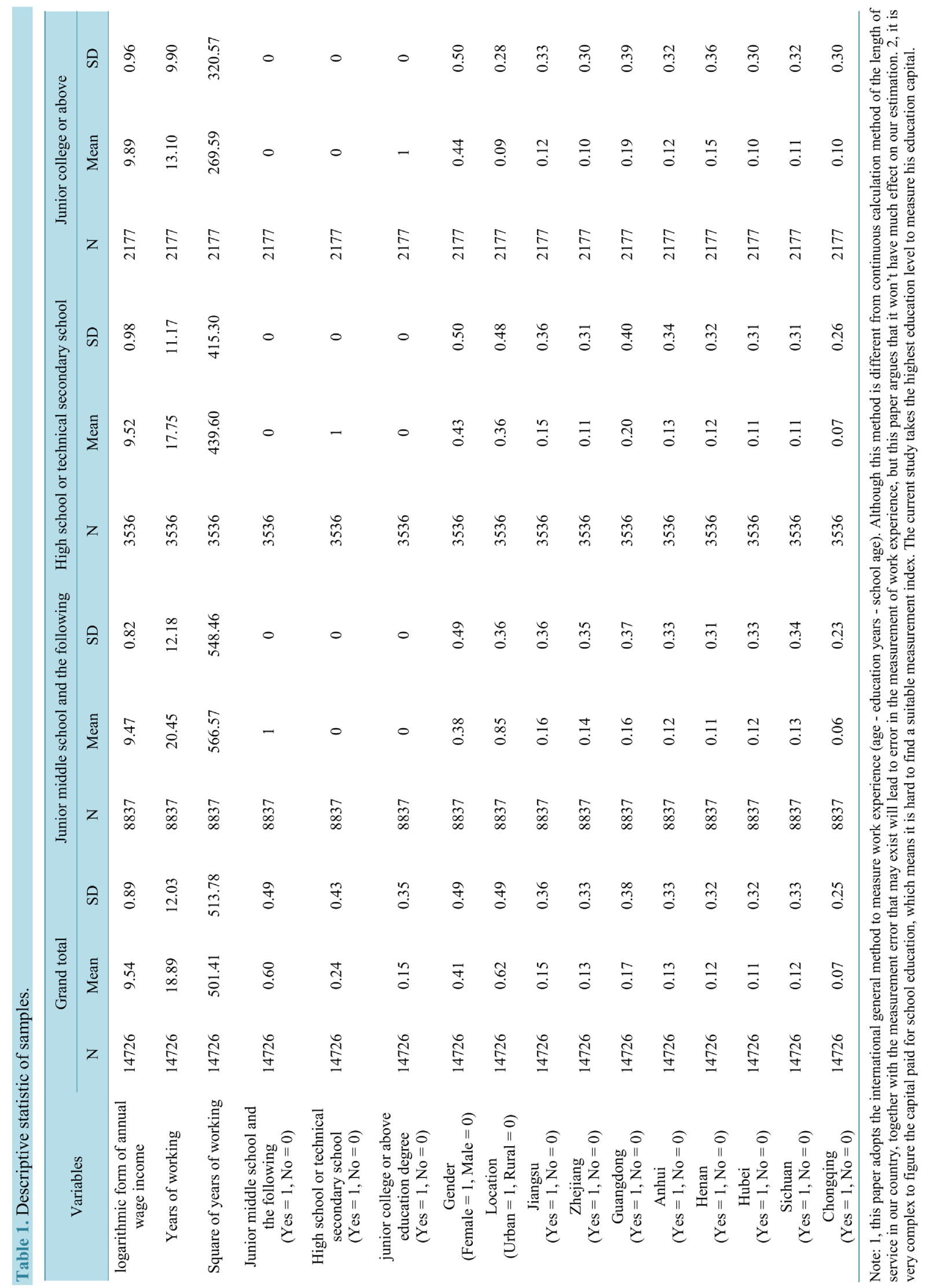


Table 2. Regression estimate ofinitial extension mincer wage equation.

\begin{tabular}{cc}
\hline & $(1)$ \\
\hline Variables & Inyinc \\
\hline edu1 & -0.0291 \\
edu3 & $(0.0179)$ \\
& $0.347^{* * *}$ \\
exp & $(0.0260)$ \\
& $0.0228^{* * *}$ \\
exp2 & $(0.00209)$ \\
& $-0.000719 * * *$ \\
Constant & $(5.18 \mathrm{e}-05)$ \\
justed $\mathrm{R}^{2}$ & $9.440^{* * *}$ \\
Observations & $(0.0221)$ \\
R-squared & 14,726 \\
\end{tabular}

Robust standard errors in parentheses. ${ }^{* *} \mathrm{p}<0.01,{ }^{* *} \mathrm{p}<0.05,{ }^{*} \mathrm{p}<0.1$.

cient of exp2 (he square of working years) is negative, inverse to exp. The relationship between wage income and years of working is not simply linear but inverted u-shaped. Ignoring other factors, workers' wage income increases with the increase of the working years at first. After reaching a certain point, it decreases with the increase of the working years. This is because works' skill levels keep improving for a period for a period with better proficiency and fitness. However when the workers' skill improve to a certain level, it may stop rising even decreasing. Because it is harder to learn new technology and more often to get tired with workers aging.

In order to eliminate other influence factors as far as possible, the current study estimates Equation (2.3) (results shown in Table 3) to isolate direct education capital variables effect on the wage premium. The regression results in Table 3 are significant in statistics, when this research adds location variables, provinces variables and gender variables.

The regress coefficient of edu1 (junior college or above) is 0.4537 . It means that when other influences are eliminated, the wage of workers who get junior college or above degree is $45.37 \%$ higher than those of high school or technical secondary school. The education wage premium of junior college or above is $45.37 \%$. workers who get high school or technical secondary school degree earn $18.3 \%$ more than those who get junior middle school and the following degree, when work experience, gender, location, region factors controlled. In other word, the education wage premium of high school or technical secondary school level is $18.3 \%$. Wage income of workers increases with the improvement of education level, and the rate of increase rises as well. According to human capital resource theory, human capital accumulation effect is the mainly source of education wage premium. Three education levels are the human capital accumulation process, which leads to the difference of human capital and then the difference in wage premium.

In addition, education capital investment is an important productivity signal in labor market. Information of firms is limited, so they can't know well about the employees. Therefore, firms usually take education capital investment as an important standard of distinguish worker productivity, to discriminate against workers with low education capital investment, to make workers with high education capital investment get more wage premium.

From the perspective of talent ability, highly educated workers generally have high innate ability. Thus they often show higher production capacity at work and get higher wage. With the improvement of education level, the number of workers gets smaller in the Labor market. Higher education capital investors are far less than the number of capital investors. The demand for high education capital investors rapidly increases, while the demand for lower education capital investors gradually reduces. Affected by supply and demand, high education capital investors can get high education capital wage premium than low education capital investors. 
Table 3. Regression estimate of further extension mincer wage equation.

\begin{tabular}{|c|c|}
\hline & (1) \\
\hline Variables & Inyinc \\
\hline \multirow[t]{2}{*}{ edu1 } & $-0.183^{* * *}$ \\
\hline & $(0.0205)$ \\
\hline \multirow[t]{2}{*}{ edu3 } & $0.454 * * *$ \\
\hline & $(0.0270)$ \\
\hline \multirow[t]{2}{*}{ exp } & $0.0273^{* * *}$ \\
\hline & $(0.00206)$ \\
\hline \multirow[t]{2}{*}{ exp2 } & $-0.000816^{* * *}$ \\
\hline & (4.99e-05) \\
\hline \multirow[t]{2}{*}{ gender } & $-0.325^{* * *}$ \\
\hline & $(0.0144)$ \\
\hline \multirow[t]{2}{*}{ location } & $0.295^{* * *}$ \\
\hline & $(0.0236)$ \\
\hline \multirow[t]{2}{*}{ projs } & $0.169 * * *$ \\
\hline & $(0.0321)$ \\
\hline \multirow[t]{2}{*}{ prozj } & $0.421 * * *$ \\
\hline & $(0.0255)$ \\
\hline \multirow[t]{2}{*}{ progd } & $0.332 * * *$ \\
\hline & $(0.0242)$ \\
\hline \multirow[t]{2}{*}{ proah } & $0.233^{* * *}$ \\
\hline & $(0.0230)$ \\
\hline \multirow[t]{2}{*}{ prohb } & $0.218^{* * *}$ \\
\hline & $(0.0248)$ \\
\hline \multirow[t]{2}{*}{ prosc } & $0.0686^{* *}$ \\
\hline & $(0.0267)$ \\
\hline \multirow[t]{2}{*}{ procq } & $0.105^{* * *}$ \\
\hline & $(0.0314)$ \\
\hline \multirow[t]{2}{*}{ Constant } & $9.222 * * *$ \\
\hline & $(0.0316)$ \\
\hline Observations & 14,726 \\
\hline R-squared & 0.121 \\
\hline
\end{tabular}

Robust standard errors in parentheses. $* * * \mathrm{p}<0.01,{ }^{* *} \mathrm{p}<0.05,{ }^{*} \mathrm{p}<0.1$.

Regression coefficient of working years variable is 0.0273 , which indicates that each worker' wage will increase by $2.73 \%$ year by year, after education, gender, urban and rural, regional factors controlled. However the trend is not sustainable. Because the coefficient of the square of working years is -0.0008 . Symbols of working years and its square variables are contrary, which means that the relationship between wages and working experience is inverted u-shaped. Wage of workers increases year by year to a certain stage, then it will decreases. Regression coefficient of the dummy variable-gender is 0.3247. After eliminating other influencing factors, male workers earns $32.47 \%$ more than female workers. The result is consistent with the fact, which is regarded as the result of gender discrimination in the labor market. 
Regression coefficient of urban or rural location dummy variable is 0.2950 , which means that workers located in the city earn $29.5 \%$ more than that of rural workers. This reflects the income inequality between urban and rural areas in China. The social phenomenon that urban wage income is higher than rural is called "city wage premium”. Agglomeration economy is an important reason. In a large city with a dense population and economic activities, the producer is more close to the consumers and suppliers. Workers is easier to find a desirable job. Both sides benefit from agglomeration economy, through which cost is saved, efficiency improve. In this way, the higher degree of economic aggregation can make higher levels of productivity. In a perfect competition market, wage of workers is decided by the marginal output. So higher productivity leads to a higher level of wage income. In addition, the cost of living in the city is higher than in the rural. Only workers who earn higher wages can afford to accept work in the city. Moreover, advantages of the city, such as policies and economic level, also are the important cause of wage differences.

As of province dummy variables, this paper takes Henan province as the as the reference group. according to the regression coefficient of various provinces and cities variables, the paper could conclude that wage income in Jiangsu, Zhejiang, Guangdong, Anhui, Hubei, Sichuan, Chongqing seven provinces and cities is higher than Henan province by $16.94 \%, 42.13 \%, 33.20 \%$, 23.29\%, 21.79\%, 6.86\% and $10.53 \%$, respectively, after eliminating other factors , such as gender, urban or rural location. Such statistical result reflects the unbalanced development in various regions the fact in China. Economy in the eastern region is relatively developed, where workers' wage income level is generally higher than that of the Midwest. Wage income in most of the central province is higher than that of the western region. The distribution presents as three steps which gradually lean from the east to the west. As the wages income level is closely as sociate with the level of economic development. Generally, wage income in economy relatively more developed regions is relatively higher than that in other regions.

After the model being further extended, the adjusted $\mathrm{R}^{2}$ increases from 0.0485 to 0.1207 , indicating that fitting degree of the further extended model Equation (2.3) has greatly improved. After stripping out the gender, urban and rural location, region affecting factors, this research gets the more accurate education wage premium at all levels, as shown in Table 4. In fact, wages of the two crowds, workers with junior middle school and the following education level and workers with high school or technical secondary school education levels, are not nearly the same as shown in the initial extended model results. However, the truth is that the latter earns more than the former. The wage gap is $18.3 \%$ according to further extended model. Workers with junior college or above education level earn far more than junior middle school and the following education level. This reflects the education capital investment has a significantly influence on personal income level. Education extension, especially the expansion of higher education, could be one of the important factors of income inequality at the present stage in China.

After the text edit has been completed, the paper is ready for the template. Duplicate the template file by using the Save As command, and use the naming convention prescribed by your journal for the name of your paper. In this newly created file, highlight all of the contents and import your prepared text file. You are now ready to style your paper.

\section{Estimation Results and Analysis}

Based on CHIPs 2007, the paper estimated and analyzed the education wage premium in partial provinces and cities in China. The findings showed that education wage premium increased with the improvement of education level in China, workers with high school or technical secondary school level earn more than those of junior middle school and the following, and less than those of junior college or above. There wasn't the phenomenon that the intellectual workers got less wage income than manual workers; source and distribution of education wage

Table 4. education wage premium on different education level.

\begin{tabular}{ccc}
\hline & \multicolumn{1}{c}{ education wage premium } & \\
\hline model & high school or technical secondary school & junior college or above \\
the initial extended model & 0 & $34.71 \%$ \\
the further extended model & $18.30 \%$ & $45.37 \%$ \\
\hline
\end{tabular}


premium was mainly realized through four mechanisms: the cumulative effect of human capital, the signal effect, talent ability, the effect of the supply and demand; as education wage premium of junior college or above education level was much more than that of high school or technical secondary school level, the education expansion, especially higher education expansion might be an important cause of personal income inequality in China; there was a huge difference of education capital wage premium between genders, urban and rural areas and between regions.

According to this paper, it can be concluded that: due to education wage premium, education has a significantly impact on personal income, therefore government should continue to develop education to improve people's living standard in China. Moreover workers with high education wage premium generally get higher productivity and more skills, development in education, especially in higher education contributes to the sound and rapid economic development. However, at a certain stage of education development, the development of education may lead to the widening income gap. Due to the above reason, the government should pay attention to the wage income adjustment to prevent personal income inequality worsening caused by education development. Finally, on account of the unbalanced distribution of income between gender, urban and rural areas, regions, the government should take action to improve the unbalanced phenomenon, and enact corresponding laws, regulations and policies to reduce the gender discrimination phenomenon and to promote the employment fairness.

\section{References}

[1] Bai X.M. and L,i Y. (2014) Influence of Education on Chinese Citizen. Research on Income Distribution with Quantile Regression Method, 4, 11-18.

[2] Fang, H.M. (2006) The College Wage Premium: Estimating a Model with Endogenous Education Choices. International Economic Review, 4.

[3] Huang, F. and Wu, C.J. (2008) A Study on Wage Premium of Provincial Capital Cities in China-A Space Econometric Analysis Based on Quantile Regression. Journal of Finance and Economics, 34.

[4] Huang, Y.B. (2006) Skill Premium, Human Capital Investment and Economic Growth. Market Modernization. No. 488.

[5] Walker, I. and Zhu, Y. (2005) The College Wage Premium, over Education, and the Expansion of Higher Education in the UK. IZA Discussion Paper No. 1627.

[6] Lai, D.S. (1997) Education Expansion and Income Inequality. Economic Research Journal.

[7] Lai, D.S. (1998) Education, Labor Market and Income Distribution. Economic Research Journal.

[8] Li, S. and Ding, S. (2009) Long-Term Change Trend of China's Urban Education Return. Social Sciences in China.

[9] Luo, C.L. (2007) Return to Education and Its Distribution in Urban China. Economic Research Journal.

[10] Fortin, N.M. (2006) Higher-Education Policies and the College Wage Premium: Cross-State Evidence from the 1990s. The American Economic Review, 96.

[11] Shu, X. (2010) Labor Market Discrimination and Consequences of the University Enrollment Expansion: A Structural Estimation Based on a Signaling Game. China Economic Quarterly, 9.

[12] Xing, C.B., Jia, S.Y. and Li, S. (2013) Regional Distribution of the Return to Education for Rural-to-Urban Migrants and Its Impact on Migration. Economic Research Journal, 11, 114-126.

[13] Zuo, W.T. (2015) Education Change Trend in Long-Term. Modern Business, 2, 286-288. 